\title{
Improved Sliding Mode Nonlinear Extended State Observer based Active Disturbance Rejection Control for Uncertain Systems with Unknown Total Disturbance
}

\author{
Wameedh Riyadh Abdul-Adheem \\ Electrical Engineering Department \\ College of Engineering, Baghdad University \\ Baghdad, Iraq
}

\author{
Ibraheem Kasim Ibraheem \\ Electrical Engineering Department \\ College of Engineering, Baghdad University \\ Baghdad, Iraq
}

\begin{abstract}
This paper presents a new strategy for the active disturbance rejection control (ADRC) of a general uncertain system with unknown bounded disturbance based on a nonlinear sliding mode extended state observer (SMESO). Firstly, a nonlinear extended state observer is synthesized using sliding mode technique for a general uncertain system assuming asymptotic stability. Then the convergence characteristics of the estimation error are analyzed by Lyapunov strategy. It revealed that the proposed SMESO is asymptotically stable and accurately estimates the states of the system in addition to estimating the total disturbance. Then, an ADRC is implemented by using a nonlinear state error feedback (NLSEF) controller; that is suggested by J. Han and the proposed SMESO to control and actively reject the total disturbance of a permanent magnet DC (PMDC) motor. These disturbances caused by the unknown exogenous disturbances and the matched uncertainties of the controlled model. The proposed SMESO is compared with the linear extended state observer (LESO). Through digital simulations using MATLAB / SIMULINK, the chattering phenomenon has been reduced dramatically on the control input channel compared to LESO. Finally, the closed-loop system exhibits a high immunity to torque disturbance and quite robustness to matched uncertainties in the system.
\end{abstract}

Keywords-extended state observer; sliding mode; rejection control; tracking differentiator; DC motor; nonlinear state feedback

\section{INTRODUCTION}

Disturbances and uncertainties widely exist in all industrial systems and bring adverse effects on performance and even stability of control systems [1]-[3]. Not surprisingly, disturbance and uncertainty rejection is a key objective in control system design. When a disturbance is measurable, it is well known that a feed forward strategy could attenuate or eliminate the influence of disturbance. However, quite often, the external disturbance cannot be directly measured or is too expensive to measure. One intuitive idea to deal with this problem is to estimate the disturbance (or the influence of the disturbance) from measurable variables, and then, a control action can be taken, based on the disturbance estimate, to compensate for the influence of the disturbance. This basic idea can be intuitively extended to deal with uncertainties where the influence of the uncertainties or unmodeled dynamics could be considered as a part of the disturbance. So, a new terminology of disturbance appeared, i.e. the total disturbance, which defines the aggregation of the input disturbances and system uncertainties (in this work the matched uncertainties) [4].

Many observers were designed in the last two decades like, high gain observers [5], disturbance observers [6] sliding mode observers [7]. The main advantages of sliding-mode observers (SMO) over their linear counterparts are that while in sliding, they are insensitive to the unknown inputs, and, moreover, they can be used to reconstruct unknown inputs which could be a combination of system disturbances, faults or nonlinearities [8]. Another useful property of SMO is that the analysis of the average value of the applied observer injection signal, the socalled equivalent injection signal, contains useful information about the mismatch between the model used to define the observer and the actual plant. In [9] comparison study of different advanced state, observers are carried out. Generally speaking, the ESO estimates the uncertainties, disturbances, and sensor noise efficiently. The beauty of ESO is that the lumped uncertainties and disturbances are estimated as a total disturbance by the ESO.

Firstly, the ESO proposed by Huang and Han in [10] is the key step of ADRC that is taking off as a technology after numerous successful applications in engineering. ESO has a simple structure, and it can estimate unmodeled dynamics precisely in many cases. Regarding ADRC, a class of nonlinear ESOs is designed to estimate the sum of both the states and external disturbances [11]. After that, Gao [12] proposed a class of linear ESOs (LESO) and provided guidance on how to choose the optimal parameters in the controller design. At present, ESO is mainly used in the control system to estimate disturbances and to compensate them via a feed-forward cancellation technique [13-15]. Moreover, ESO can be extended to multi-input-multi-output systems as well [15].

A class of nonlinear extended state observers (NESO) was proposed by J. Han [16] in 1995 as a unique observer design. It is rather independent of a mathematical model of the plants, thus achieving inherent robustness. It was tested and verified in key industrial control problems $[17,18]$. 
ADRC design method was proposed to deal with both robust stability and performance specifications for a multivariable process with time delay in the input [19]. Veluvolu K.C et al. in [20] incorporated A sliding mode term into the nonlinear observer for a class of uncertain nonlinear systems so as to improve the estimation accuracy. While others proposed robust sliding mode control for uncertain time-delay systems against the mismatched uncertainties and matched external disturbance [21]. The researchers in [22] suggested a nonlinear disturbance observer-based robust control method for nonlinear systems in the presence of mismatched disturbances and uncertainties. People in [23] presented an adaptive fuzzy observer design for the fuzzy system with unknown output disturbance and bounded constant parameter uncertainty. The fuzzy observer was designed under the existence of uncertain parameters and output disturbance.

The application side of this work is highly related to fields where the disturbances or unwanted signals or uncertainties need to be measured or estimated. So, the main application of The technique proposed in this paper is used as an essential part of the Active Disturbance Rejection Control (ADRC) which consists of a tracking differentiator, extended state observer, and nonlinear state error feedback to solve some problems in various reference applications with promising results. The ADRC as an entire system has been applied in the medical field for the management of an artificial blood pump for terminal congestive heart failure [24]. In real manufacturing applications, the ADRC method has been used to accomplish the high-precision control of ball screw feed drives [25]. In [26], The ADRC based Load Frequency Control (LFC) has considered for both, single-area power system and multi-area power system network, where the area control error (ACE) is controlled in the existence of uncertainties in system dynamics and external disturbances, which are all estimated by the extended state observer. Also, a dual-loop ADRC algorithm that is used for an active hydraulic suspension system, which can help the six-wheel off-road vehicle to improve the performance transition [27]. In computer networks, the ADRC technique has been applied to maintain the stability of a network operating system in the presence of a delay caused by the network (sensor-controller delay and delay of the controller actuator), this delay is considered as a disturbance and is handled by the extended state observer [28]. In the field of robots, the ADRC is useful in quad helicopter control due to superiority to solve control problems and disturbance estimation of the nonlinear models with uncertainty and intense disturbances superiority [29].

The contribution of this paper is the design and robustness verification of the SMESO based ADRC in the presence of system matched uncertainties and exogenous disturbances for the PMDC motor. Firstly, we replace the ESO of the standard ADRC by a nonlinear observer designed by sliding mode technique. Then, a proper mathematical model for the PMDC motor is derived based on state-space representation by a careful choice of the states to get a model that fits the standard form of the chain integrators nonlinear form used in the design of the ADRC strategy. The mathematical model includes of an exogenous disturbance, which is called the load torque for the PMDC motor, the total disturbances, and the uncertainties are all modeled and lumped in an augmented state to be estimated perfectly later by the proposed SMESO. Next, the SMESO is modeled and designed under the assumption that the closedloop system is asymptotically stable. Otherwise, a suitable state feedback or another control design technique has to be set and applied to stabilize the unstable system. We show after that the stability of the proposed SMESO is already guaranteed if the nonlinear gain of the SMESO is above the critical gain threshold imposed by the SMESO observer stability. Finally, several numerical simulations are performed, and the results are compared with the standard ADRC proposed by J. Han ADRC $[10,11,16,24]$ based on LESO.

The rest of the paper is organized as follows: Section II presents the traditional ADRC, components of ADRC, and total disturbance estimation and rejection via ESO. The derivation of the mathematical model of the PMDC is introduced in section III. While the proposed SMESO design is presented and discussed in details, i.e. the derivation of the state-space model of the proposed observer and the stability conditions for the proposed SMESO are all discussed in section IV. Section V illustrates the numerical simulations and some comments and highlights on the work. Finally, conclusions are given in section VI.

\section{ACtive Disturbance ReJection CONTROL (ADRC)}

The ADRC can be constructed by combining the transient profile generation, the nonlinear feedback combination, and the total disturbance estimation and rejection; the ADRC takes the form as shown in Fig. 1 [30].

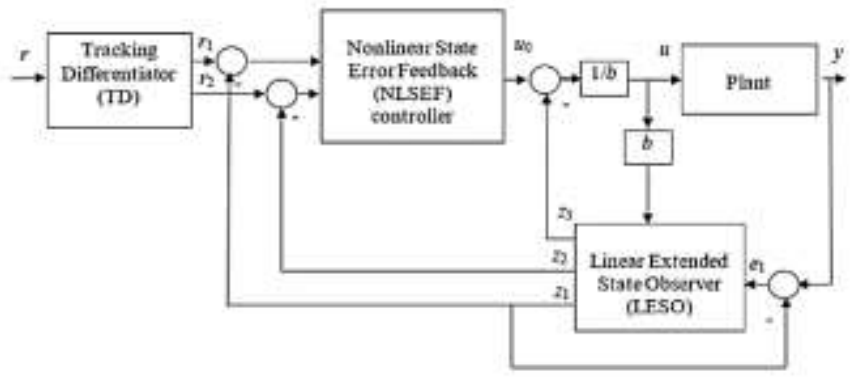

Fig. 1. ADRC topology

The desired transient profile is obtained by solving the following differential equation [30]:

$$
\left.\begin{array}{l}
\dot{r}_{1}=r_{2} \\
\dot{r}_{2}=-R \operatorname{sign}\left(r_{1}-r(t)+\frac{r_{2}\left|r_{2}\right|}{2 r}\right)
\end{array}\right\}
$$

where $r_{1}$ is the desired trajectory and $r_{2}$ is its derivative. Note that, the parameter $R$ is an application dependent and it is set accordingly to speed up or slow down the transient profile. It is in this sense that (1) is denoted as the "tracking differentiator" of $r(t)$.

As a control law, State Error Feedback employs a nonlinear combination of the present, accumulative, and predictive forms of the tracking error and has, for a long time, ignored other possibilities of this combination that are potentially much more effective. As an alternative, Han [11] proposed the following nonlinear function: 


$$
f a l(e, \alpha, \delta)=\left\{\begin{array}{cc}
\frac{e}{\delta^{1-\alpha}} & |x| \leq \delta \\
|e|^{\alpha} \operatorname{sign}(e) & |x| \geq \delta
\end{array}\right.
$$

An important concept called the total disturbance [31], its estimation, and rejection will be introduced in the following. Although such concept is, in general, applicable to most nonlinear multi-input-multi-output (MIMO) time varying systems, we will use a general second-order single-inputsingle-output (SISO) example for the sake of simplicity and clarity. Considering a single-input-single-output (possibly nonlinear) system with disturbance, depicted by [31]:

$$
y^{(n)}(t)=f\left(y(t), \dot{y}(t), \ldots, y^{(n-1)}(t), d(t), t\right)+b u(t)
$$

where $y^{(l)}$ denotes the $l^{\text {th }}$ derivative of the output $y$ and $u$ and $d$ denote the input and the disturbance, respectively. This description represents a wide range of systems, which could be linear, or nonlinear and time invariant or time varying. To simplify the notation, the time variable will be dropped if no confusion is caused. Letting $x_{1}=y, x_{2}=\dot{y}, \ldots, x_{n}=y^{(n-1)}$, one has

$$
\left.\begin{array}{l}
\dot{x}_{i}=x_{i+1}, \quad i=1, \ldots, n-1 \\
\dot{x}_{n}=f\left(x_{1}, x_{2}, \ldots, x_{n}, d, t\right)+b u
\end{array}\right\}
$$

Choose a new state as

$$
\begin{aligned}
& x_{n+1}=f\left(x_{1}, x_{2}, \ldots, x_{n}, d, t\right) \\
& \dot{x}_{n+1}=h(t)
\end{aligned}
$$

with

$$
h(t)=\dot{f}\left(x_{1}, x_{2}, \ldots, x_{n}, d, t\right)
$$

A LESO is designed to estimate all of the states and lumped uncertainties and disturbance term $f$,

$$
\left.\begin{array}{l}
\dot{\hat{x}}_{i}=\hat{x}_{i+1}+\beta_{i}\left(y-\hat{x}_{1}\right), i=1, \ldots, n \\
\dot{\hat{x}}_{n+1}=\beta_{n+1}\left(y-\hat{x}_{1}\right)
\end{array}\right\}
$$

It is obvious that both the influences of model dynamics (including unmodeled dynamics and uncertainties) and external disturbance are estimated in the LESO. Only the relative degree of the system under consideration is required in the LESO design. Therefore, the significant feature of LESO is that it requires minimum information about a dynamic system. Various extensions have been made to extend the basic LESO design to a wider range of dynamic systems [30].

\section{MATHEMATICAL MODELING OF THE PERMANENT MAGNET DC (PMDC) MOTOR}

Most electromechanical systems driven by DC motor such as weight belt feeder exhibits nonlinear behaviour because of motor friction, motor saturation, and quantization noise in the measurement sensors. The dynamics of the system are dominated by the motor. The PMDC motor is an example of electromechanical systems with electrical and mechanical components. Table I lists the description of the PMDC motor parameters.

The total equivalent inertia, $J_{e q}$ and total equivalent damping, $B_{e q}$ at the armature of the motor are given by:

$$
J_{e q}=J_{m}+\frac{J_{L}}{n^{2}}, \quad B_{e q}=B_{m}+\frac{B_{L}}{n^{2}}
$$

The differential equation of the PMDC motor with exogenous disturbance is given by:

$$
\begin{aligned}
& \ddot{\omega}=-\frac{R_{a} B_{e q}+K_{t} K_{b}}{L_{a} J_{e q}} \omega-\frac{\left(L_{a} B_{e q}+R_{a} J_{e q}\right)}{L_{a} J_{e q}} \dot{\omega}+\frac{1}{n} \frac{K_{t}}{L_{a} J_{e q}} v_{a}+ \\
& \frac{1}{n} \frac{1}{J_{e q}} \dot{T}_{L}+\frac{1}{n} \frac{R_{a}}{L_{a} J_{e q}} T_{L} \\
& \text { Let } \quad x_{1}=\omega, \quad x_{2}=\dot{x}_{1}=\dot{\omega}
\end{aligned}
$$

Then, the state space representation of the PMDC motor after simplifications becomes:

$$
\begin{aligned}
& \dot{x}_{1}=x_{2} \\
& \begin{aligned}
\dot{x}_{2}= & -\frac{R_{a} B_{e q}+}{L_{a} J_{e q}} K_{t} K_{b} \\
& \left.\quad+\frac{L_{a}}{K_{t}} \dot{T}_{L}+\frac{R_{a}}{K_{t}} T_{L}\right) \\
& \quad \text { (9) }
\end{aligned} \\
& \text { Let } d=\frac{L_{a}}{K_{t}} \dot{T}_{L}+\frac{R_{a}}{K_{t}} T_{L}
\end{aligned}
$$

Where $d$ is the equivalent exogenous disturbance at the input. Finally

$$
\left.\begin{array}{l}
\dot{x}_{1}=x_{2} \\
\dot{x}_{2}=-\frac{R_{a} B_{e q}+K_{t} K_{b}}{L_{a} J_{e q}} x_{1}-\frac{\left(L_{a} B_{e q}+R_{a} J_{e q}\right)}{L_{a} J_{e q}} x_{2}+ \\
\frac{1}{n} \frac{K_{t}}{L_{a} J_{e q}}\left(v_{a}+d\right) \\
y=x_{1}
\end{array}\right\}
$$

TABLE I. PMDC MOTOR PARAMETERS

\begin{tabular}{|l|l|}
\hline Parameter (unit) & Description \\
\hline $\mathrm{Va}(\mathrm{V})$ & Applied voltage \\
\hline $\mathrm{Vb}(\mathrm{V})$ & Back EMF of the motor \\
\hline $\mathrm{Ra}(\Omega)$ & Armature resistance \\
\hline $\mathrm{La}(\mathrm{H})$ & Armature inductance \\
\hline $\mathrm{Jm}(\mathrm{kg} / \mathrm{m} 2)$ & Inertia of the motor \\
\hline $\mathrm{Bm}(\mathrm{N} . \mathrm{s} / \mathrm{m})$ & Friction coefficient of the motor \\
\hline $\mathrm{N}$ & gearbox ratio \\
\hline $\mathrm{JL}(\mathrm{kg} / \mathrm{m} 2)$ & Inertia of the load \\
\hline $\mathrm{BL}(\mathrm{N} . \mathrm{s} / \mathrm{m})$ & Friction coefficient of the load \\
\hline$\omega \mathrm{m}(\mathrm{rad} / \mathrm{s})$ & the speed of the motor \\
\hline$\omega(\mathrm{rad} / \mathrm{s})$ & the speed of the shaft \\
\hline $\mathrm{Va}(\mathrm{V})$ & Applied voltage \\
\hline
\end{tabular}

\section{Proposed Sliding Mode Extended State ObSERVER} (SMESO)

In this section, the proposed SMESO is presented, and the stability analysis is considered based on Lyapunov method. Figure 2 Shows the ADRC with the proposed SMESO. 


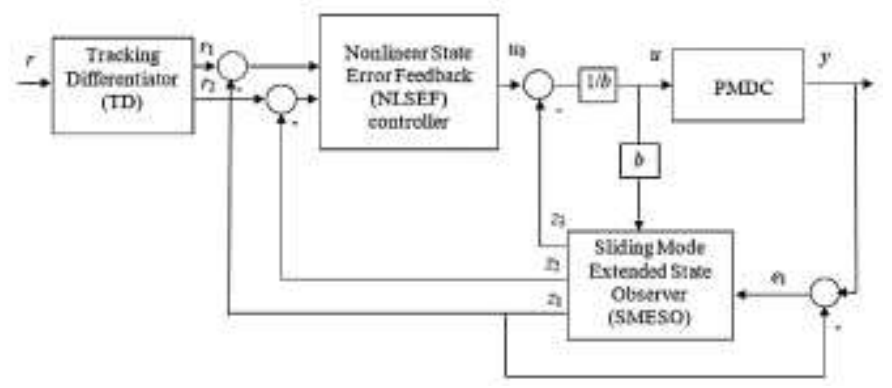

Fig. 2. ADRC topology based the SMESO

\section{A. The Nonlinear State-Space Model representation of the Proposed SMESO}

The proposed SMESO has the following state space representation:

$$
\dot{\boldsymbol{Z}}=\boldsymbol{F} \boldsymbol{Z}+\boldsymbol{B}_{1} u+\boldsymbol{B}_{2} g\left(y-z_{1}\right)
$$

where $\boldsymbol{Z} \in \boldsymbol{R}^{(n+1) \times 1}$, is a vector that contains the estimated plant states and the total disturbance, $\dot{\boldsymbol{Z}} \in \boldsymbol{R}^{(n+1) \times 1}, \boldsymbol{B}_{1} \in$ $\boldsymbol{R}^{(n+1) \times 1}, \boldsymbol{B}_{2} \in R^{(n+1) \times 1}, \boldsymbol{F} \in \boldsymbol{R}^{(n+1) \times(n+1)}$.

$$
\begin{aligned}
& \boldsymbol{Z}=\left[\begin{array}{llll}
z_{1} & z_{2} & \ldots & z_{n+1}
\end{array}\right]^{T}, \quad \dot{\boldsymbol{Z}}=\left[\begin{array}{llll}
\dot{z}_{1} & \dot{z}_{2} & \ldots & \dot{z}_{n+1}
\end{array}\right]^{T} \\
& \boldsymbol{F}=\left[\begin{array}{cccccc}
0 & 1 & 0 & 0 & \cdots & 0 \\
0 & 0 & 1 & 0 & \cdots & 0 \\
0 & 0 & 0 & 1 & \cdots & 0 \\
0 & \vdots & \vdots & \vdots & \ddots & \vdots \\
0 & 0 & 0 & 0 & \cdots & 1 \\
0 & 0 & 0 & 0 & 0 & 0
\end{array}\right] \\
& \boldsymbol{B}_{1}=\left[\begin{array}{lllll}
0 & 0 & \ldots 1 & 0
\end{array}\right]^{T}, \quad \boldsymbol{B}_{2}=\left[\begin{array}{llll}
\beta_{1} & \beta_{2} & \ldots & \beta_{n+1}
\end{array}\right]^{T}
\end{aligned}
$$

Now,

$$
\begin{aligned}
g\left(y-z_{1}\right)= & K_{\alpha}\left|y-z_{1}\right|^{\alpha} \operatorname{sign}\left(y-z_{1}\right)+K_{\beta} \mid y- \\
& \left.z_{1}\right|^{\beta}\left(y-z_{1}\right)
\end{aligned}
$$

\section{$\underline{\text { Assumption } 1}$}

$g($.$) is an odd nonlinear function with the following$ features,

- $g(0)=0$

- $g(l)=k(l) . l$ where $k_{\min } \leq k(l)<\infty$.

Rewriting (12) as,

$$
g\left(y-z_{1}\right)=\left(K_{\alpha} \frac{\left|y-z_{1}\right|^{\alpha}}{\left(y-z_{1}\right)} \operatorname{sign}\left(y-z_{1}\right)+\right.
$$

$\left.K_{\beta}\left|y-z_{1}\right|^{\beta}\right)\left(y-z_{1}\right)$

Since

$$
\operatorname{sign}\left(y-z_{1}\right)=y-z_{1} /\left|y-z_{1}\right|, \text { for }\left|y-z_{1}\right| \neq 0 .
$$

Then,

$$
k\left(y-z_{1}\right)=K_{\alpha}\left|y-z_{1}\right|^{\alpha-1}+K_{\beta}\left|y-z_{1}\right|^{\beta}
$$

and,

$$
g\left(y-z_{1}\right)=k\left(y-z_{1}\right)\left(y-z_{1}\right)
$$

Or equivalently, $g\left(e_{1}\right)=k\left(e_{1}\right)\left(e_{1}\right)$ where, $e_{1}=y-z_{1}$, and

$$
k\left(e_{1}\right)=K_{\alpha}\left|e_{1}\right|^{\alpha-1}+K_{\beta}\left|e_{1}\right|^{\beta}
$$

For $n=2$, the nonlinear state space representation of the proposed SMESO is given as:

$$
\begin{aligned}
\dot{z}_{1}= & z_{2}+\beta_{1}\left(K_{\alpha}\left|y-z_{1}\right|^{\alpha} \operatorname{sign}\left(y-z_{1}\right)\right. \\
& \left.+K_{\beta}\left|y-z_{1}\right|^{\beta}\left(y-z_{1}\right)\right) \\
\dot{z}_{2}= & z_{3}+b u+\beta_{2}\left(K_{\alpha}\left|y-z_{1}\right|^{\alpha} \operatorname{sign}\left(y-z_{1}\right)\right. \\
& \left.\quad+K_{\beta}\left|y-z_{1}\right|^{\beta}\left(y-z_{1}\right)\right) \\
\dot{z}_{3}= & \beta_{3}\left(K_{\alpha}\left|y-z_{1}\right|^{\alpha} \operatorname{sign}\left(y-z_{1}\right)\right. \\
+ & \left.K_{\beta}\left|y-z_{1}\right|^{\beta}\left(y-z_{1}\right)\right)
\end{aligned}
$$

Figure 3 illustrates the proposed SMESO with order 3.

\section{B. Stability Analysis of the SMESO}

Consider an uncertain 2nd order single input-single output nonlinear plant described by:

$$
\begin{aligned}
& \dot{x}_{1}=x_{2} \\
& \dot{x}_{2}=f\left(x_{1}, x_{2}\right)+b(u+d) \\
& y=x_{1}
\end{aligned}
$$

where $x=\left[\begin{array}{ll}x_{1} & x_{2}\end{array}\right]^{T} \in R^{2}$ is the state vector, $u \in R$ is the control input, $y \in R$ is the plant output, $d \in R$ is bounded exogenous disturbance, and $f: R^{2 \times 1} \rightarrow R$ with $f(0,0)=0$. The total disturbance state is represented by the augmented state

$$
x_{3}=f\left(x_{1}, x_{2}\right)+b d=\varphi\left(x_{1}, x_{2}, d\right)
$$

Then,

$$
\dot{x}_{3}=\dot{f}\left(x_{1}, x_{2}\right)+b \dot{d}=\psi\left(x_{1}, x_{2}, \dot{d}\right)
$$

\section{Assumption 2}

1) $d(t)$ is continuously differentiable, both $d(t)$ and $d \dot{(t)}$ are bounded and $\dot{d} \rightarrow 0$ as $t \rightarrow \infty$, and $d(t) \in D$ (a compact subset of $R$ ).

2) $f\left(x_{1}, x_{2}\right)$ and $\dot{f}\left(x_{1}, x_{2}\right)$ are both locally Lipschitz functions in $x_{1}$ and $x_{2}$.

3) The closed-loop system of (15) w.r.t (1), (2), and (16) given below is uniformly asymptotically stable. i.e. $\dot{\boldsymbol{x}}$ approaches zero as $t$ goes to infinity.

4) Both $\varphi\left(x_{1}, x_{2}, d\right)$ and $\psi\left(x_{1}, x_{2}, d\right)$ are both locally Lipschitz functions in $x_{1}$ and $x_{2}$, bounded, and uniformly in $d$, over the domain of interest.

5) Only the output y is available.

6) $\left|\frac{\partial f}{\partial x_{\mathrm{d}}}\right|<L_{1}$, $\left|\frac{\partial f}{\partial x_{2}}\right|<L_{2}$.

The 3 order nonlinear SMESO that estimates the system's states and the total disturbance is given by (14) rewritten as:

$$
\left.\begin{array}{l}
\dot{z}_{1}=z_{2}+\beta_{1} g\left(y-z_{1}\right) \\
\dot{z}_{2}=z_{3}+\beta_{2} g\left(y-z_{1}\right)+b u \\
\dot{z}_{3}=\beta_{3} g\left(y-z_{1}\right)
\end{array}\right\}
$$


where $\mathbf{z}=\left[\begin{array}{lll}z_{1} & z_{2} & z_{3}\end{array}\right]^{T} \in \boldsymbol{R}^{3 \times 1}$ is the state vector of the SMESO, and $B=\left[\beta_{1} \beta_{2} \beta_{3}\right]^{T} \in \boldsymbol{R}^{3 \times 1}$ is a parameter vector.

Lemma 1: Consider the plant dynamics in (15) with the augmented state $x_{3}$ to be observed by SMESO in (16). Then, the error dynamics can be described by,

$$
\dot{\boldsymbol{e}}=M \boldsymbol{e}+N \Delta
$$

Where $\boldsymbol{e}=\left[\begin{array}{lll}e_{1} & e_{2} & e_{3}\end{array}\right]^{T}=\left[\begin{array}{lll}z_{1}-x_{1} & z_{2}-x_{2} & z_{3}-x_{3}\end{array}\right]^{T} \in \boldsymbol{R}^{3 \times 1}$ is the error vector,

$$
\begin{gathered}
\Delta\left(x_{1}, x_{2}, \dot{d}\right)=-\psi\left(x_{1}, x_{2}, \dot{d}\right)=-\dot{f}\left(x_{1}, x_{2}\right)-b \dot{d} \in \boldsymbol{R}^{3 \times 1}, \\
M=\left[\begin{array}{lll}
-\beta_{1} k\left(e_{1}\right) & 1 & 0 \\
-\beta_{2} k\left(e_{1}\right) & 0 & 1 \\
-\beta_{3} k\left(e_{1}\right) & 0 & 0
\end{array}\right] \in \boldsymbol{R}^{3 \times \mathbf{3}}, \quad N=\left[\begin{array}{l}
0 \\
0 \\
1
\end{array}\right] \in \boldsymbol{R}^{3 \times \mathbf{1}}
\end{gathered}
$$

\section{Proof:}

To obtain the error dynamics subtract (15) from (16), then

$$
\begin{gathered}
\dot{z}_{1}-\dot{x}_{1}=z_{2}-x_{2}+\beta_{1} g\left(y-z_{1}\right) \\
\dot{z}_{2}-\dot{x}_{2}=z_{3}-f\left(x_{1}, x_{2}\right)-b(u+d)+\beta_{2} g\left(y-z_{1}\right) \\
+b u \\
=z_{3}-x_{3}+\beta_{2} g\left(y-z_{1}\right) \\
\dot{z}_{3}=-\dot{f}\left(x_{1}, x_{2}\right)-b \dot{d}+\beta_{3} g\left(y-z_{1}\right)
\end{gathered}
$$

Then

$$
\begin{aligned}
& \dot{e}_{1}=e_{2}+\beta_{1} g\left(-e_{1}\right) \\
& \dot{e}_{2}=e_{3}+\beta_{2} g\left(-e_{1}\right)
\end{aligned}
$$

$\dot{e}_{3}=\Delta\left(x_{1}, x_{2}, \dot{d}\right)+\beta_{3} g\left(-e_{1}\right)$

Since $g($.$) is odd function and g\left(e_{1}\right)=k\left(e_{1}\right) e_{1}$, then,

$$
\begin{aligned}
& \dot{e}_{1}=-\beta_{1} k\left(e_{1}\right) e_{1}+e_{2} \\
& \dot{e}_{2}=-\beta_{2} k\left(e_{1}\right) e_{1}+e_{3} \\
& \dot{e}_{3}=-\beta_{3} k\left(e_{1}\right) e_{1}+\Delta\left(x_{1}, x_{2}, \dot{d}\right)
\end{aligned}
$$

Hence,

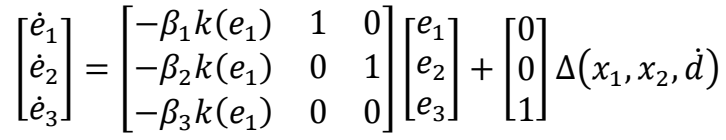

and in a compact form

$$
\dot{\boldsymbol{e}}=M \boldsymbol{e}+N \Delta \text {. } \square
$$

Lemma 2: Consider the plant dynamics given in (15) with assumption 2 holds. Also, consider $\left|\frac{\partial f}{\partial x_{1}}\right|<L_{1},\left|\frac{\partial f}{\partial x_{2}}\right|<L_{2}$, then $\lim _{t \rightarrow \infty} \Delta\left(x_{1}, x_{2}, \dot{d}\right)=0$.

\section{Proof:}

Writing $\dot{f}\left(x_{1}, x_{2}\right)=\frac{\partial f}{\partial x_{1}} \dot{x}_{1}+\frac{\partial f}{\partial x_{2}} \dot{x}_{2}$. For bounded first partial derivatives and if and only if assumption 2 holds true, then

$$
\lim _{t \rightarrow \infty} \Delta\left(x_{1}, x_{2}, \dot{d}\right)=\lim _{t \rightarrow \infty}-\dot{f}\left(x_{1}, x_{2}\right)-b \dot{d}=0 . \square
$$

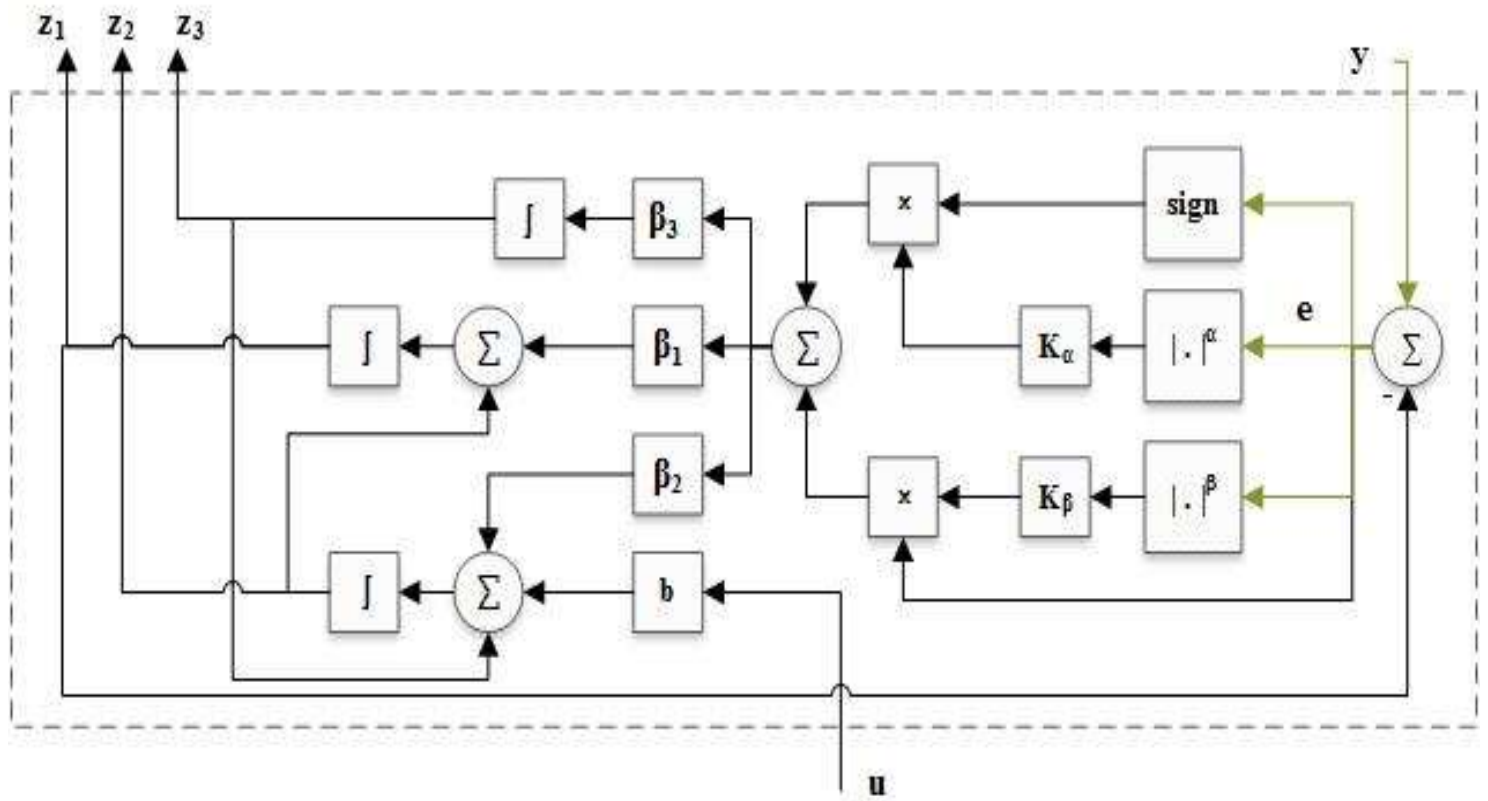

Fig. 3. Proposed SMESO for ADRC

.Theorem 1: Consider the plant in (15) and the nonlinear extended state observer (16) with the error dynamics in Lemma 1 with $S=e_{1}$, where, $S: R \rightarrow R$ is the switching function for the SMESO Then,
1) The SMESO is globally asymptotically stable if $k\left(e_{1}\right)>k_{c r}$

where $k_{c r}=\frac{\beta_{3}}{\beta_{2} \beta_{1}}$, that is for any initial conditions $\boldsymbol{e}(0)$, we have $\lim _{t \rightarrow \infty} \boldsymbol{e}(t)=0$. 
2) The SMESO has a sliding mode given that (17) is satisfied.

Proof:

Assume the candidate positive definite, radially unbounded Lyapunov function $V_{S M E S O}=\frac{1}{2} \boldsymbol{e}^{\boldsymbol{T}} \boldsymbol{e}$. Then,

$\dot{V}_{S M E S O}=\boldsymbol{e}^{\boldsymbol{T}} \dot{\boldsymbol{e}}$

Moreover,

$$
\begin{aligned}
\dot{V}_{\text {SMESO }}= & {\left[\begin{array}{lll}
e_{1} & e_{2} & e_{3}
\end{array}\right]\left[\begin{array}{lll}
-\beta_{1} k\left(e_{1}\right) & 1 & 0 \\
-\beta_{2} k\left(e_{1}\right) & 0 & 1 \\
-\beta_{3} k\left(e_{1}\right) & 0 & 0
\end{array}\right]\left[\begin{array}{l}
e_{1} \\
e_{2} \\
e_{3}
\end{array}\right] } \\
& +\left[\begin{array}{lll}
e_{1} & e_{2} & e_{3}
\end{array}\right] \Delta\left(x_{1}, x_{2}, \dot{d}\right) e_{3}
\end{aligned}
$$
to

according to lemma $2, \lim _{t \rightarrow \infty} \Delta\left(x_{1}, x_{2}, \dot{d}\right)=0$, this leads

$\dot{V}_{S M E S O}=\left[\begin{array}{lll}e_{1} & e_{2} & e_{3}\end{array}\right]\left[\begin{array}{lll}-\beta_{1} k\left(e_{1}\right) & 1 & 0 \\ -\beta_{2} k\left(e_{1}\right) & 0 & 1 \\ -\beta_{3} k\left(e_{1}\right) & 0 & 0\end{array}\right]\left[\begin{array}{l}e_{1} \\ e_{2} \\ e_{3}\end{array}\right]$

Or in compact form

$\dot{V}_{S M E S O}=\boldsymbol{e}^{T} \boldsymbol{P e}$

where $\boldsymbol{e}^{\boldsymbol{T}}=\left[\begin{array}{lll}e_{1} & e_{2} & e_{3}\end{array}\right], \boldsymbol{P}=\left[\begin{array}{lll}-\beta_{1} k\left(e_{1}\right) & 1 & 0 \\ -\beta_{2} k\left(e_{1}\right) & 0 & 1 \\ -\beta_{3} k\left(e_{1}\right) & 0 & 0\end{array}\right]$

If $\boldsymbol{P}$ is a stable matrix then,

$\dot{V}_{S M E S O}(\boldsymbol{e})<0$ for $\boldsymbol{e} \neq 0, \dot{V}_{S M E S O}(\boldsymbol{e})=0$ for $\boldsymbol{e}=0$

A tabular method based on Routh-Hurwitz criterion can be used to determine the stability limits of the matrix $\boldsymbol{P}$ as follows:

Firstly, compute the characteristic equation of the matrix $\boldsymbol{P}$

$$
\begin{aligned}
& |\lambda \boldsymbol{I}-\boldsymbol{P}|=0 \\
& \left|\begin{array}{ccc}
\lambda+\beta_{1} k(e) & -1 & 0 \\
\beta_{2} k(e) & \lambda & -1 \\
\beta_{3} k(e) & 0 & \lambda
\end{array}\right|=0
\end{aligned}
$$

Then, the characteristic equation of the matrix $\boldsymbol{P}$ is given as

$$
\lambda^{3}+\beta_{1} k(e) \lambda^{2}+\beta_{2} k(e) \lambda+\beta_{3} k(e)=0
$$

Next, fill the table that has 4 rows like the following

TABLE II. ROUTH STABILITY CRITERION

\begin{tabular}{|c|c|}
\hline 1 & $\beta_{2} k(e)$ \\
\hline$\beta_{1} k(e)$ & $\beta_{3} k(e)$ \\
\hline$\frac{\beta_{1} \beta_{2} k(e)^{2}-\beta_{3} k(e)}{\beta_{1} k(e)}=\beta_{2} k(e)-\frac{\beta_{3}}{\beta_{1}}$ & 0 \\
\hline$\beta_{3} k(e)$ & 0 \\
\hline
\end{tabular}

Finally, based on above; it can be concluded that for stability, the coefficients with the nonlinear gains must satisfy

$$
\beta_{2} k(e)-\frac{\beta_{3}}{\beta_{1}}>0, \quad k(e)>\frac{\beta_{3}}{\beta_{2} \beta_{1}},
$$

Then, the critical gain $k_{C r}=\frac{\beta_{3}}{\beta_{2} \beta_{1}} . \square$

To prove 2, consider a Lyapunov function candidate:

$V=\frac{1}{2} S^{2}$

A sufficient condition for the existence of a sliding mode is that

$$
\dot{V}=S \dot{S}<0 \text { or, } e_{1} \dot{e}_{1}<0
$$

This can be explained as follows, from proof of point (1) and given (17) true, the SMESO is asymptotically stable, i.e., that, then means, $\dot{e}_{1}<0$. Or $\lim _{t \rightarrow \infty} \boldsymbol{e}(t)=0$ with negative $e(t)$, then $\dot{e}_{1}>0$. in both cases 0 .

$$
e_{1} \dot{e}_{1}=\left(z_{1}-x_{1}\right)\left[\left(z_{2}-x_{2}\right)-\beta_{1} k\left(z_{1}-x_{1}\right)\left(z_{1}-x_{1}\right)\right]<
$$

\section{NUMERICAL SIMULATIONS}

The ADRC based on the proposed SMESO and the PMDC motor mathematical models are designed and numerically simulated using Matlab® /Simulink ${ }^{\circledR}$ as shown in Figure 4. These models are summarized below:

\section{LESO:}

$$
\begin{aligned}
& \dot{z}_{1}=z_{2}+\beta_{1}\left(e_{1}\right) \\
& \dot{z}_{2}=z_{3}+\beta_{2}\left(e_{1}\right)+b u \\
& \dot{z}_{3}=\beta_{3}\left(e_{1}\right) \\
& e_{1}=y-z_{1}
\end{aligned}
$$

\section{SMESO:}

$$
\begin{aligned}
& \dot{z}_{1}=z_{2}+\beta_{1} k\left(e_{1}\right) e_{1} \\
& \dot{z}_{2}=z_{3}+\beta_{2} k\left(e_{1}\right) e_{1}+b u \\
& \dot{z}_{3}=\beta_{3} k\left(e_{1}\right) e_{1} \\
& k\left(e_{1}\right)=K_{\alpha}\left|e_{1}\right|^{\alpha-1}+K_{\beta}\left|e_{1}\right|^{\beta}
\end{aligned}
$$

TD:

$$
\begin{aligned}
& \dot{r}_{1}=r_{2} \\
& \dot{r}_{2}=-R \operatorname{sign}\left(r_{1}-r+\frac{r_{2}\left|r_{2}\right|}{2 R}\right)
\end{aligned}
$$

\section{NLSEF controller:}

$$
u_{0}=\operatorname{fal}\left(r_{1}-z_{1}, \alpha_{1}, \delta_{1}\right)+f a l\left(r_{2}-z_{2}, \alpha_{2}, \delta_{2}\right)
$$

\section{PMDC motor:}

$$
\begin{gathered}
\dot{x}_{1}=x_{2} \\
\dot{x}_{2}=f\left(x_{1}, x_{2}\right)+b(u+d) \\
f\left(x_{1}, x_{2}\right)=-a_{1} x_{1}-a_{2} x_{2}, \\
u=u_{0}-\frac{z_{3}}{b}, a_{1}=\frac{R_{a} B_{e q}+K_{t} K_{b}}{L_{a} J_{e q}}, a_{2}=\frac{\left(L_{a} B_{e q}+R_{a} J_{e q}\right)}{L_{a} J_{e q}} \\
b=\frac{1}{n} \frac{K_{t}}{L_{a} J_{e q}}
\end{gathered}
$$


The values of the parameters for the whole system are listed in tables III-VII.

TABLE III. NLSEF PARAMETERS

\begin{tabular}{|c|c|}
\hline Parameter & Value \\
\hline$\delta_{1}$ & 0.5656 \\
\hline$\delta_{2}$ & 0.8269 \\
\hline$\alpha_{1}$ & 0.4679 \\
\hline$\alpha_{2}$ & 0.7440 \\
\hline
\end{tabular}

TABLE IV. THE PARAMETERS OF THE PROPOSED SMESO

\begin{tabular}{|c|c|}
\hline Parameter & Value \\
\hline$\alpha$ & 0.6825 \\
\hline$\beta$ & 0.9048 \\
\hline $\mathrm{k}_{\alpha}$ & 0.6138 \\
\hline $\mathrm{k}_{\beta}$ & 0.0809 \\
\hline
\end{tabular}

TABLE V. LESO PARAMETERS

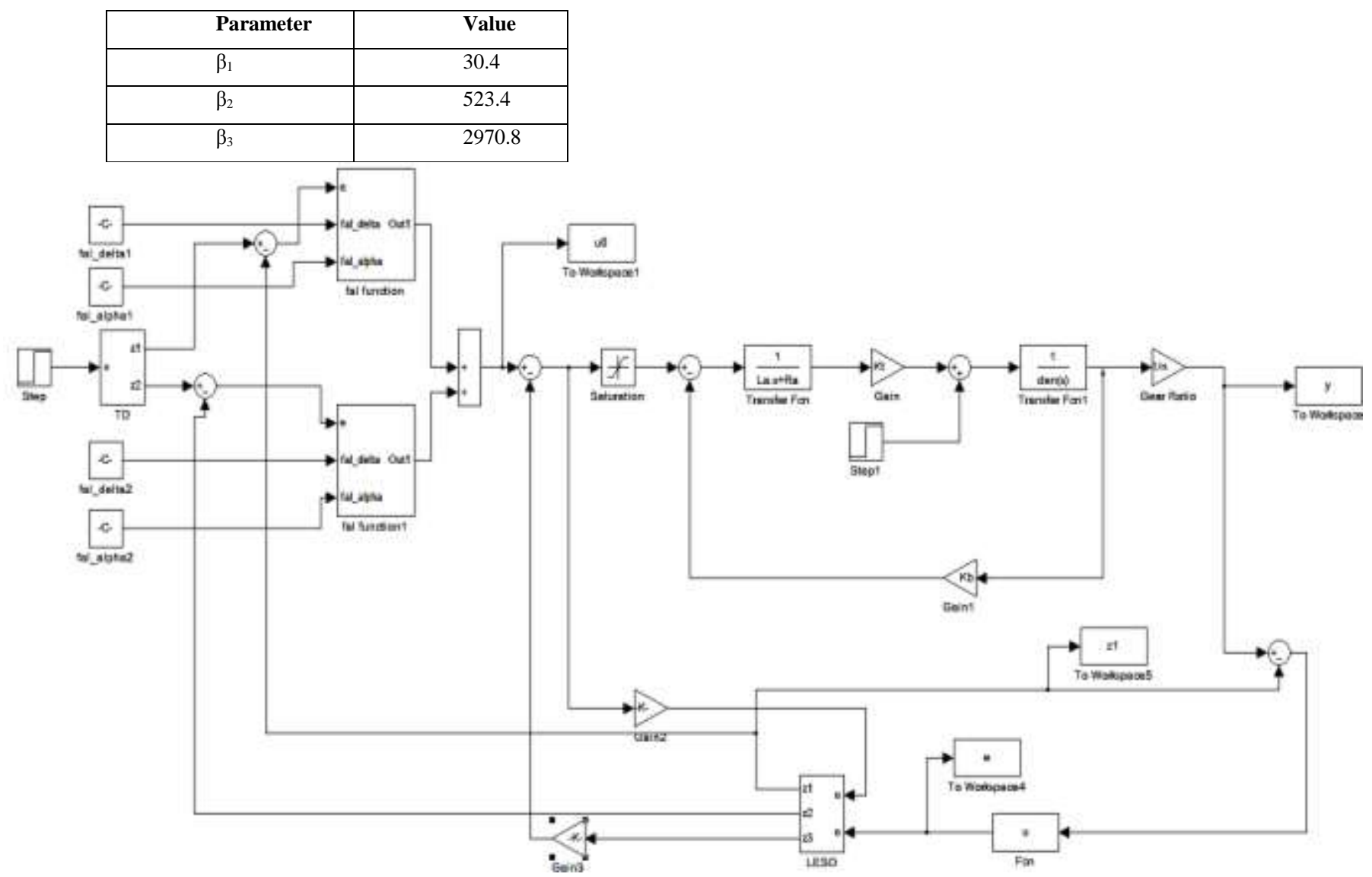

Fig. 4. The Simulink ${ }^{\circledR}$ model for the proposed ADRC based on the SMESO

The numerical simulations are done by using Matlab® ODE45 solver for the models with continuous states. This Runge-Kutta ODE45 solver is a fifth-order method that performs a fourth-order estimate of the error. The reference input to the system is constant angular velocity equals to $1 \mathrm{rad} / \mathrm{s}$
TABLE VI. TD PARAMETERS

\begin{tabular}{|l|l|}
\hline Parameter & Value \\
\hline $\mathrm{R}$ & 100 \\
\hline
\end{tabular}

TABLE VII. PMDC MOTOR PARAMETERS

\begin{tabular}{|l|l|}
\hline Parameter & Value \\
\hline $\mathrm{R}_{\mathrm{a}}$ & 0.1557 \\
\hline $\mathrm{L}_{\mathrm{a}}$ & 0.82 \\
\hline $\mathrm{K}_{\mathrm{b}}$ & 1.185 \\
\hline $\mathrm{K}_{\mathrm{t}}$ & 1.1882 \\
\hline $\mathrm{n}$ & 3.0 \\
\hline $\mathrm{J}_{\mathrm{eq}}$ & 0.2752 \\
\hline $\mathrm{b}_{\mathrm{eq}}$ & 0.3922 \\
\hline
\end{tabular}


significant reduction in chattering (compare Fig. 5(a) and Fig. 6(a)). This removal is due to the inclusion of a nonlinear function in the SMESO, and the behaviour of this observer provides a counter effect to the discontinuous function in the NLSEF. It is the main advantage of the using ADRC that relies in large extent on the total disturbance observer in cancelling the disturbances and system uncertainties than depending totally on the nonlinear controller to achieve this goal. As can be seen from the graph of the control signal for the case of the proposed SMESO that less energy will be used than the LESO to get the required tracking and disturbance cancellation. Moreover, the range of the state error $e_{1}$ reduced from [$0.013037,0.023414]$ for LESO to [-0.001810, 0.010721] for SMESO. This reduction reflects the accuracy of the proposed SMESO to estimate the states of the system in addition to the total disturbance which comprises the exogenous disturbance and the uncertainties. An Objective Performance Index (OPI) is proposed to evaluate the performance of the proposed SMESO observer, which is represented as:

$$
\mathrm{OPI}=w_{0} \times \mathrm{ITAE}+w_{1} \times \mathrm{IAU}+w_{2} \times \mathrm{ISU}
$$

Where,

ITAE $=\int_{0}^{20} t \times|r-y| d t$ is the integration of the time absolute error for the output signal,

IAU $=\int_{0}^{20}\left|u_{0}\right| d t$ is the integration of absolute of the NLSEF control signal, and

ISU $=\int_{0}^{20} u_{0}^{2} d t$ is the integration of square of the NLSEF control signal.

The ITAE is commonly used in the performance measure of the closed-loop feedback control system to minimize the error signal. While the second term IAU minimizes the amplitude of the control signal $u_{0}$ through time. The peaking phenomenon that occurs at the starting has been reduced dramatically for both observers by including the ISU in the OPI. Table VIII shows the numerical simulation results with $w_{0}, w_{1}$, and $w_{2}$ equal to $0.6420,1.000$, and 0.4906 respectively. The OPI in the case of LESO is 5.3502 and the OPI for the proposed SMESO are 3.3712 . This means a reduction equals to $37 \%$.

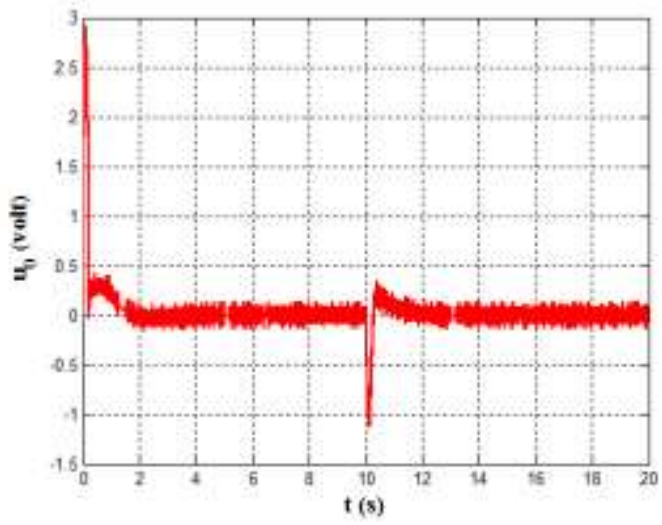

(a)

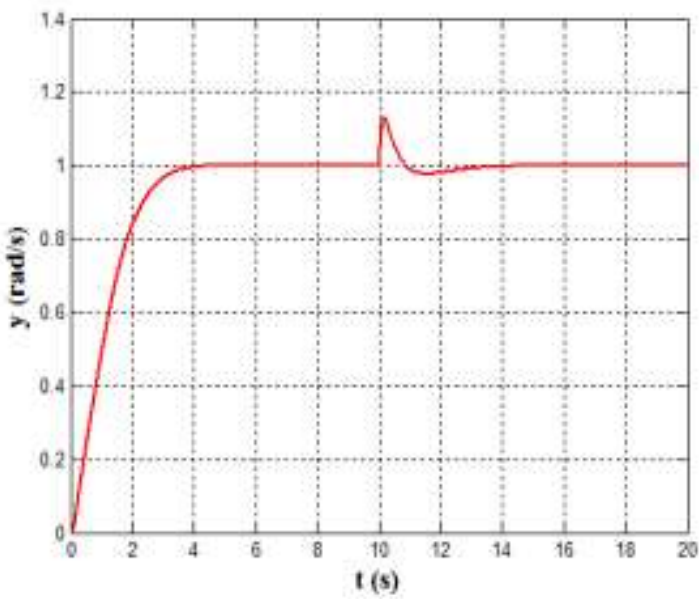

(b)

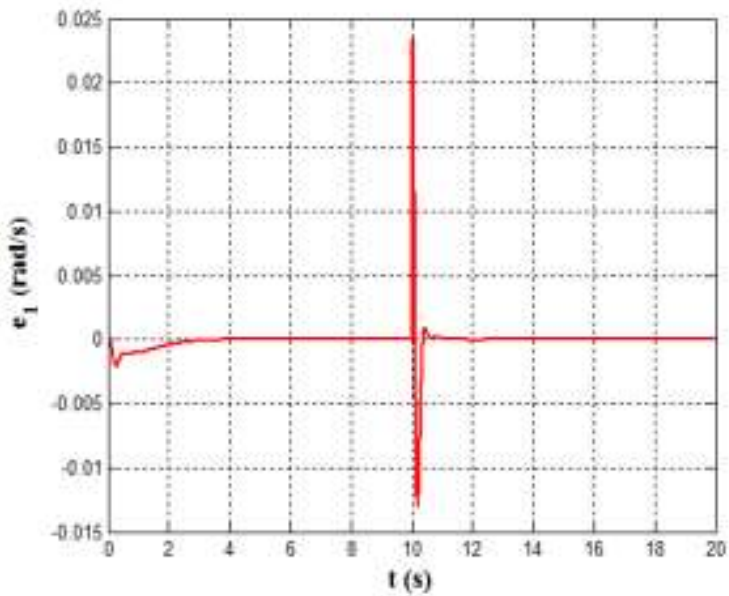

(c)

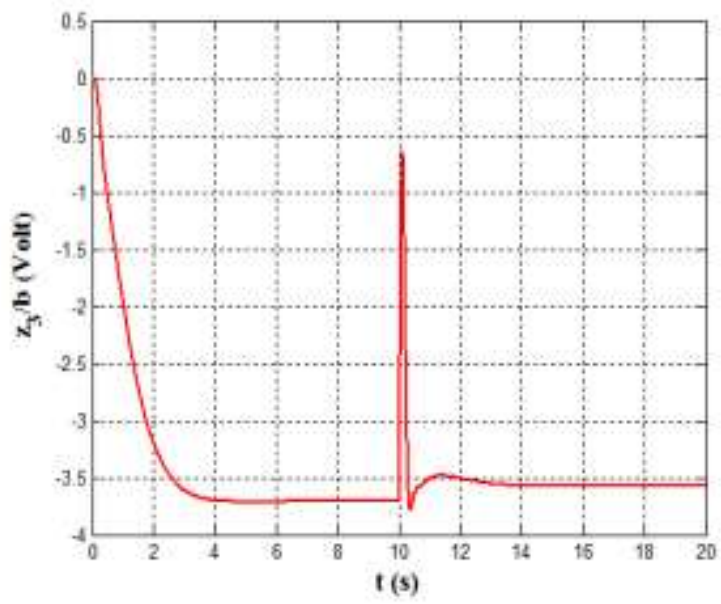

(d)

Fig. 5. The simulation results of the ADRC based on LESO, (a) The control signal u0 (b) The plant output y (c) The LESO state error e1 (d) The estimated input equivalent total disturbance 


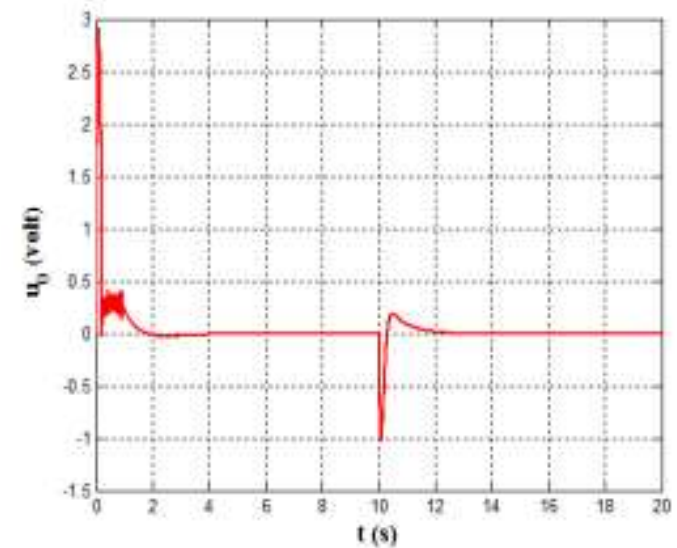

(a)

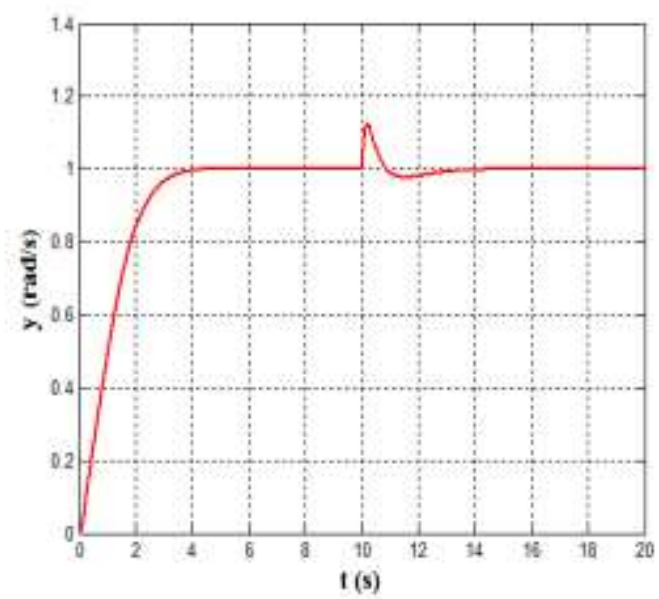

(b)

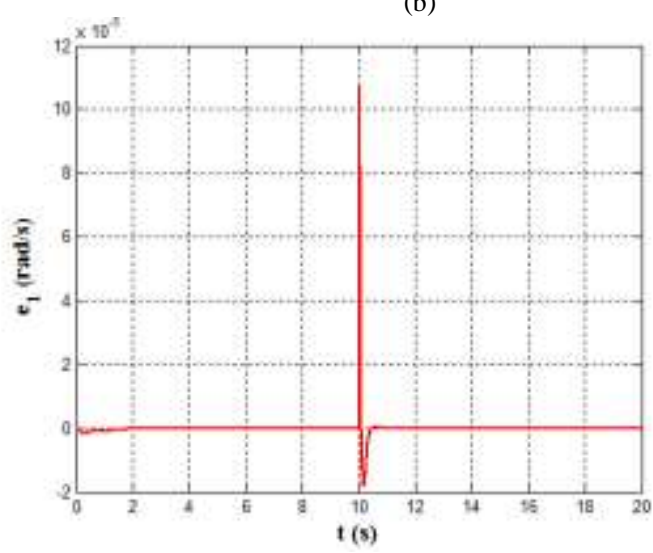

(c)

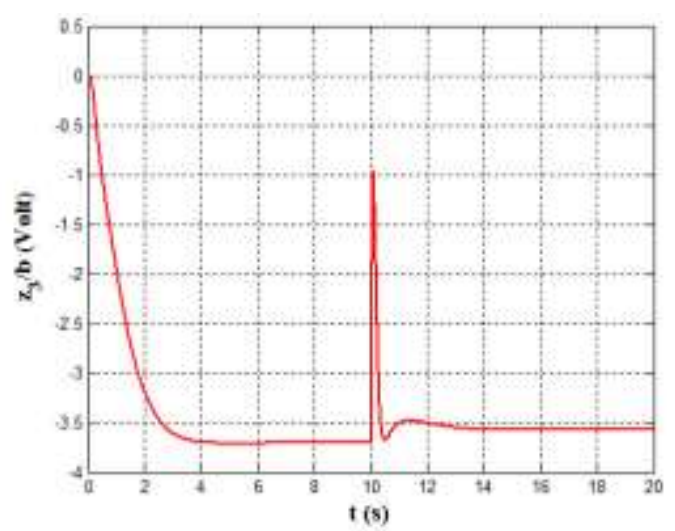

(d)

Fig. 6. The simulation results of the ADRC based on SMESO, (a) The control signal u0 (b) The plant output y (c) The SMESO state error e1 (d) The estimated input equivalent total disturbance

TABLE VIII. THE NUMERICAL SIMULATION RESUltS

\begin{tabular}{|l|l|l|}
\hline $\begin{array}{l}\text { Performance } \\
\text { indices }\end{array}$ & LESO & SMESO \\
\hline ITAE & 3.5224 & 2.3070 \\
\hline IAU & 2.2751 & 1.2701 \\
\hline ISU & 1.6586 & 1.2637 \\
\hline OPI & 5.3502 & 3.3712 \\
\hline
\end{tabular}

TABLE IX. The PARAMETERS OF THE PROPOSED SMESO

(Case 1)

\begin{tabular}{|l|l|}
\hline Parameter & Value \\
\hline$\alpha$ & 0.6825 \\
\hline$\beta$ & 0.9048 \\
\hline $\mathrm{k}_{\alpha}$ & 0.1000 \\
\hline $\mathrm{k}_{\beta}$ & 0.1000 \\
\hline
\end{tabular}

TABLE X. The Parameters of THE PROPOSED SMESO

(case 2)

\begin{tabular}{|l|l|}
\hline Parameter & Value \\
\hline$\alpha$ & 0.7000 \\
\hline$\beta$ & 0.9000 \\
\hline $\mathrm{k}_{\alpha}$ & 0.0100 \\
\hline $\mathrm{k}_{\beta}$ & 0.0100 \\
\hline
\end{tabular}


TABLE XI. THE PARAMETERS OF THE PROPOSED SMESO

(case 3)

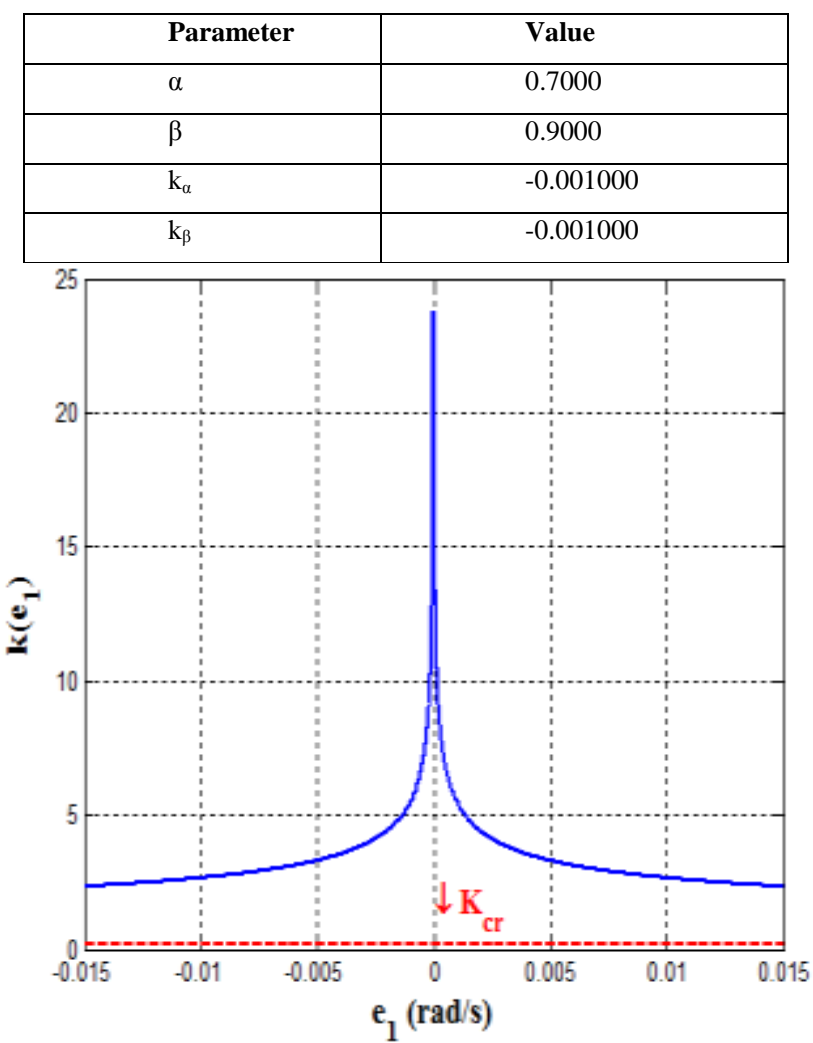

Fig. 7. The gain function of the proposed SMESO with its parameters listed in table VI

The nonlinear gain function $k\left(e_{1}\right)$ over the domain of the state error for the SMESO is shown in figure 7. The value of $k\left(e_{1}\right)$ at $e_{1}=0$ goes to infinity as can be seen from (13). But because MATLAB draws a sampled version of the signal, it does not appear graphically as supposedly to be. As the gain function $k\left(e_{1}\right)$ is reduced to approach the critical gain $\mathrm{k}_{\mathrm{cr}}$ the ESO shows oscillation behaviour because that the roots of (18) approaches the imaginary axis, with $k\left(e_{1}\right)$ violates $(17)$, the roots are in the right half plane. This phenomenon can be shown for three cases as shown in figures 8-10 by using the parameters listed in tables IX-XI for the SMESO.

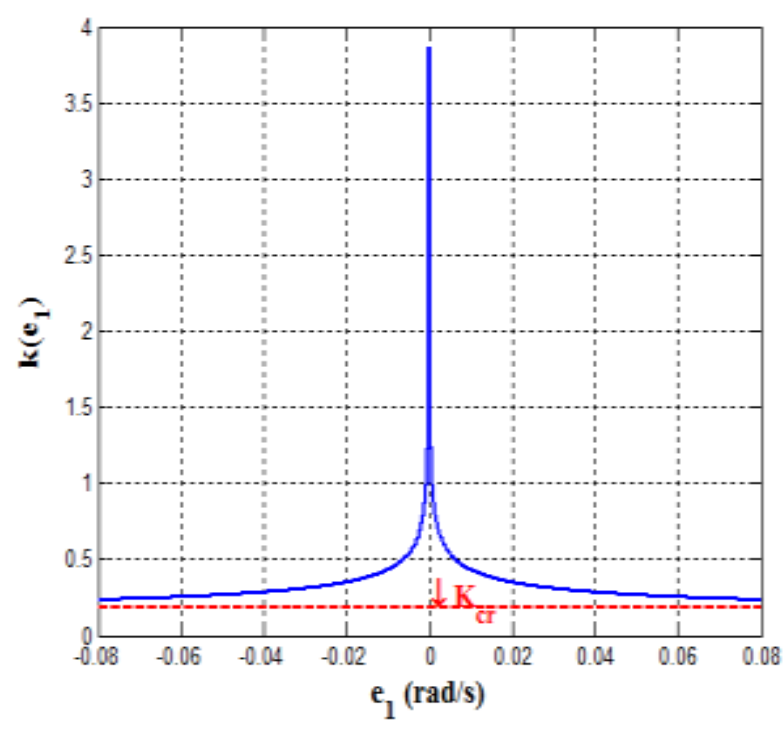

(a)

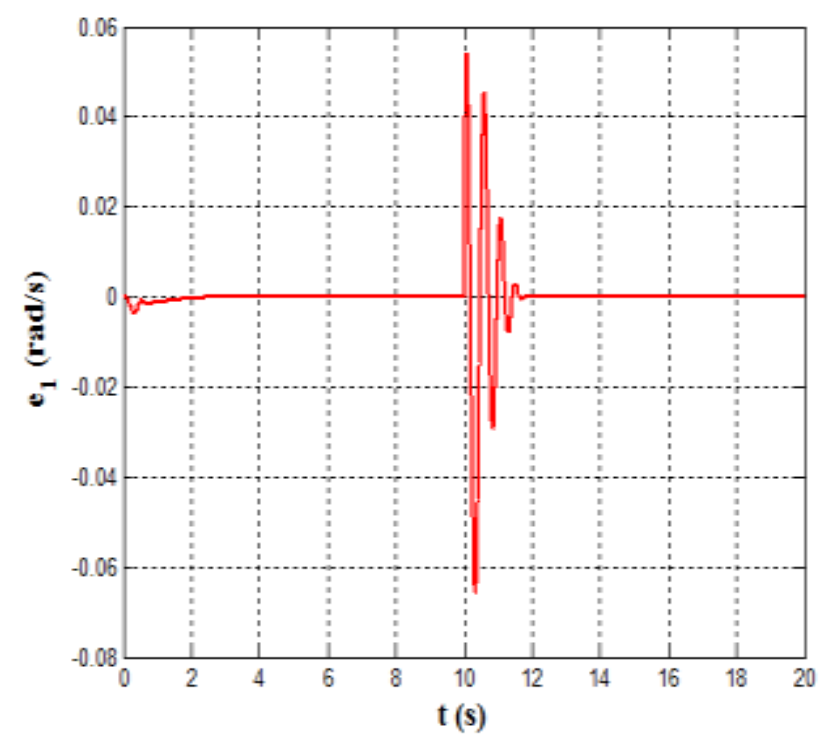

(b)

Fig. 8. Reducing the gain function for case 1, (a) The gain function (b) The oscillation behaviour in e1 


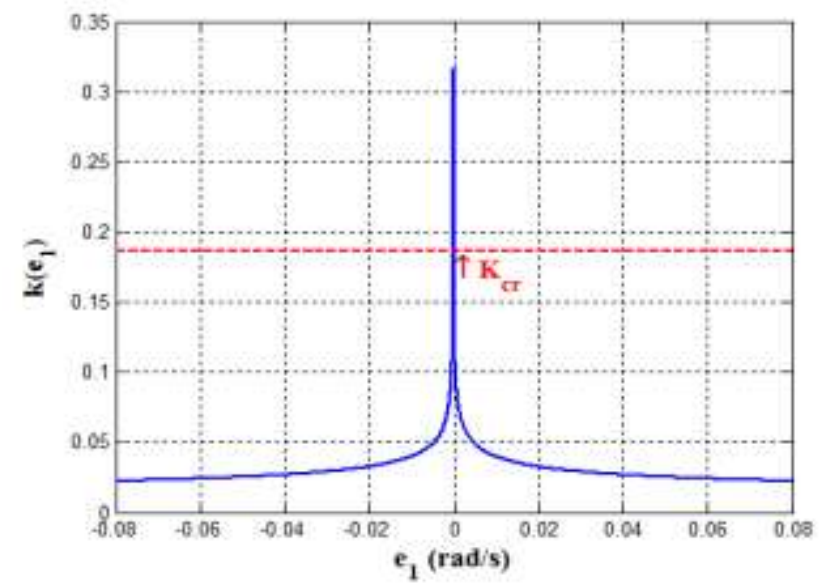

(a)

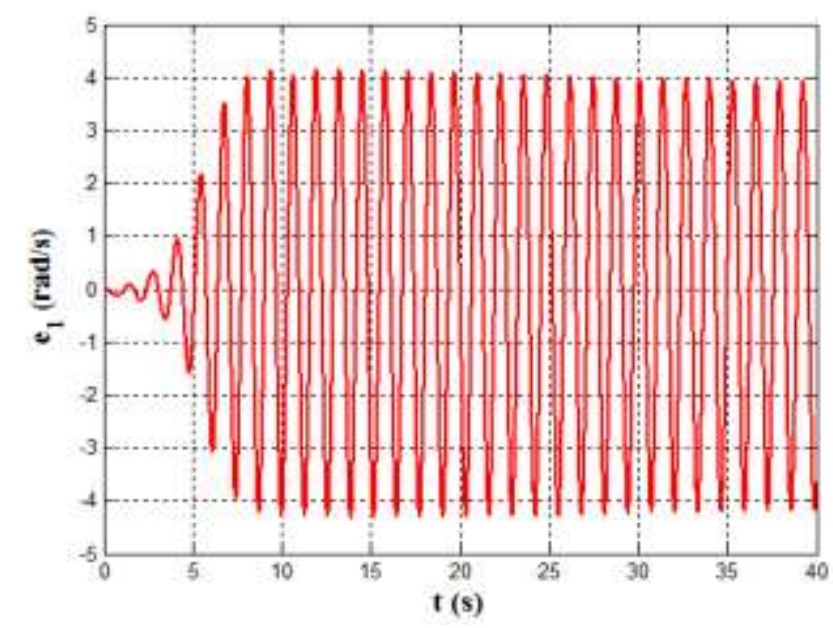

(b)

Fig. 9. Reducing the gain function for case 2, (a) The gain function (b) The oscillation behaviour in $\mathrm{e} 1$

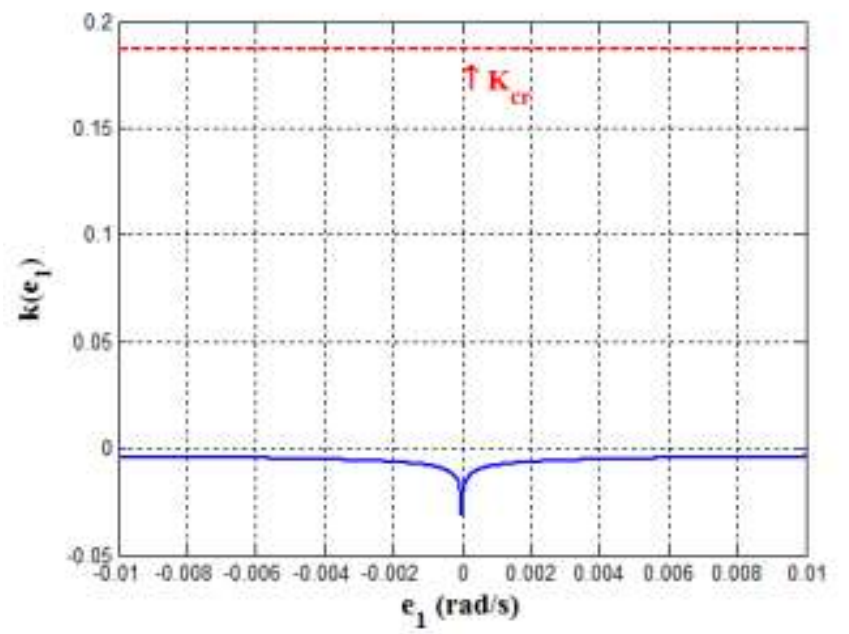

(a)

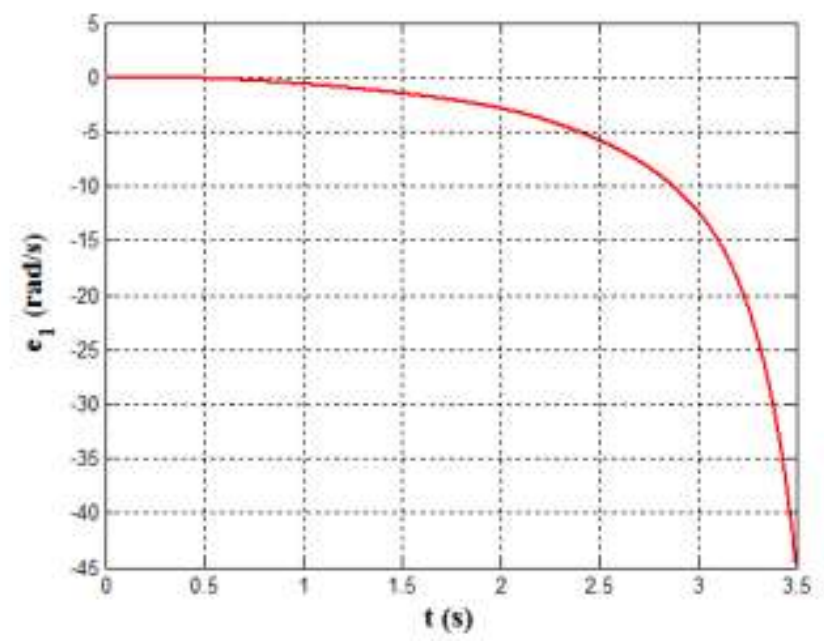

(b)

Fig. 10. Reducing the gain function for case 3, (a) The gain function (b) The oscillation behaviour in $\mathrm{e}_{1}$

The immunity of the system to the parameter uncertainty is tested for two cases. The first case is tested be varying the factor of load viscous friction $B_{L}$ in the range [1,5] N.s/m and the OPI is evaluated for that range as shown in figure 11(a). Next, the second case includes varying the value of the armature resistance $R_{a}$ in the range $[0.1,1] \Omega$. The OPI for the second case is shown in figure 11(b). It can be inferred that the OPI of the proposed SMESO is less than that for the LESO for the underlying operating range. Figures 12 and 13 show the performance of the ADRC against system uncertainties for the PMDC motor. Figure 12 is the variation in $B_{L}$, while Figure 13 is for variation in $R_{a}$. Finally, the main characteristic of the proposed design of the SMESO is asymptotic stability which can be verified by plotting $e_{1} \dot{e}_{1}$ versus time. The negative definiteness of (18) is clear from the figure 14.

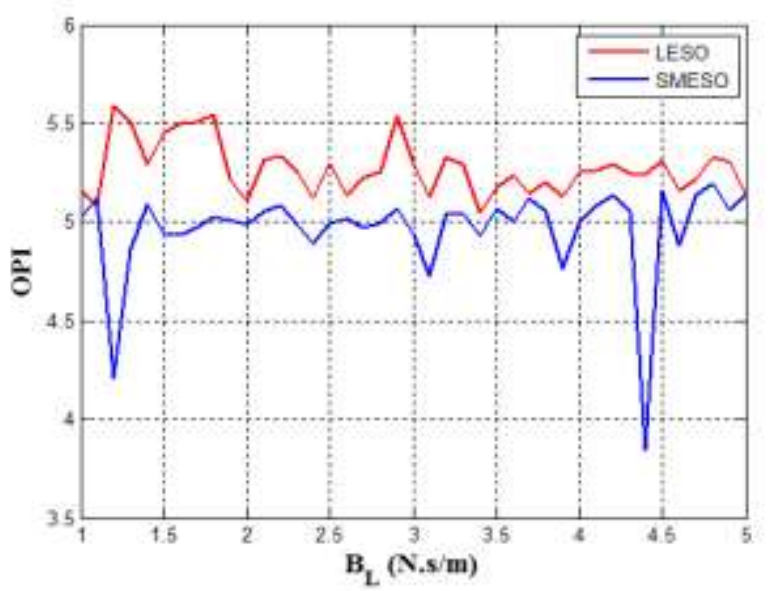

(a) 


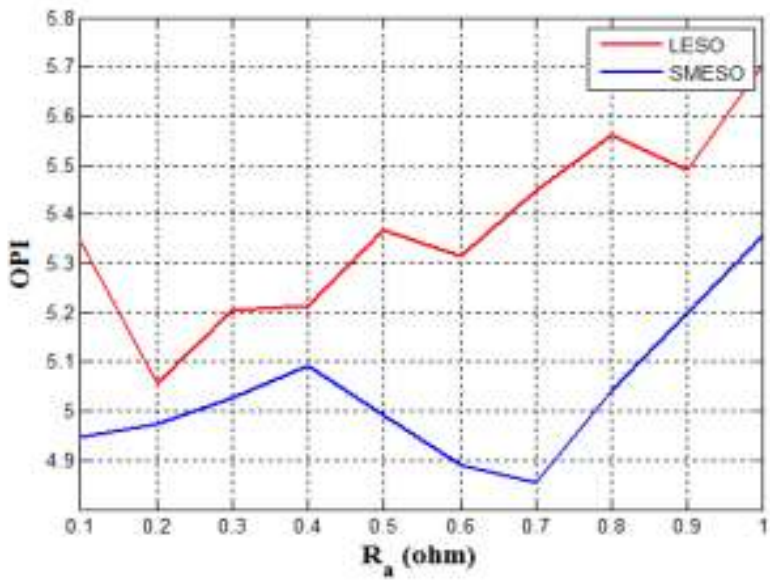

(b)

Fig. 11. The OPI against uncertainty, (a) uncertainty in BL (b) uncertainty in $\mathrm{Ra}$

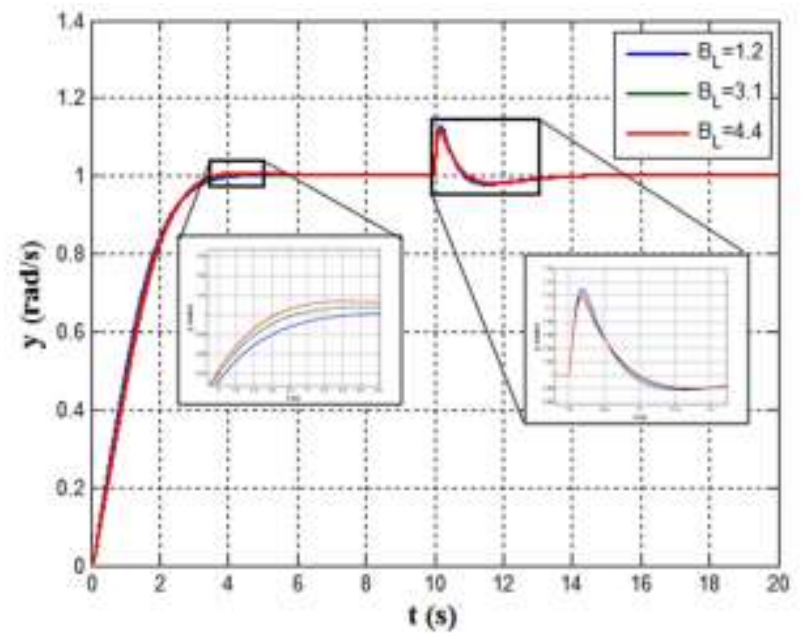

(a)

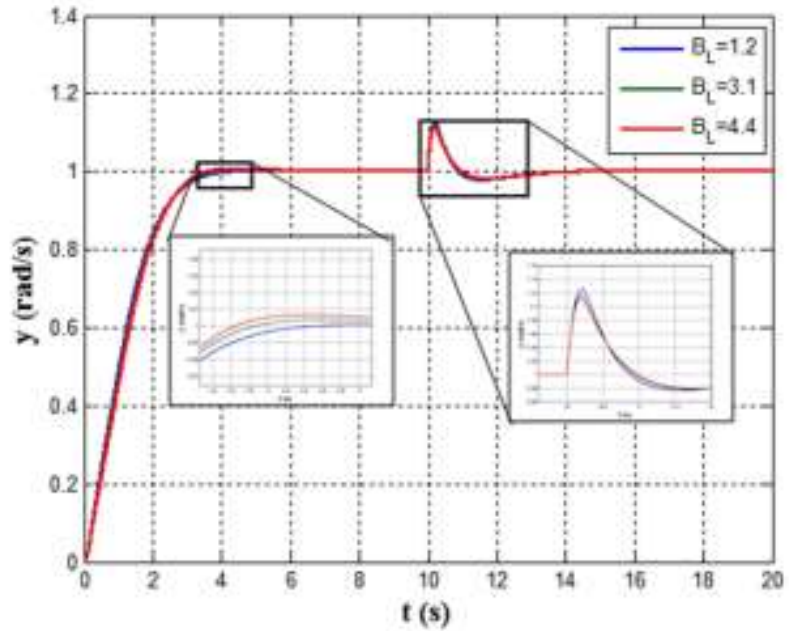

(b)

Fig. 12. The plant output $\mathrm{y}$ in presence of uncertainty in the parameter BL (N.s/m), (a) for LESO (b) for SMESO

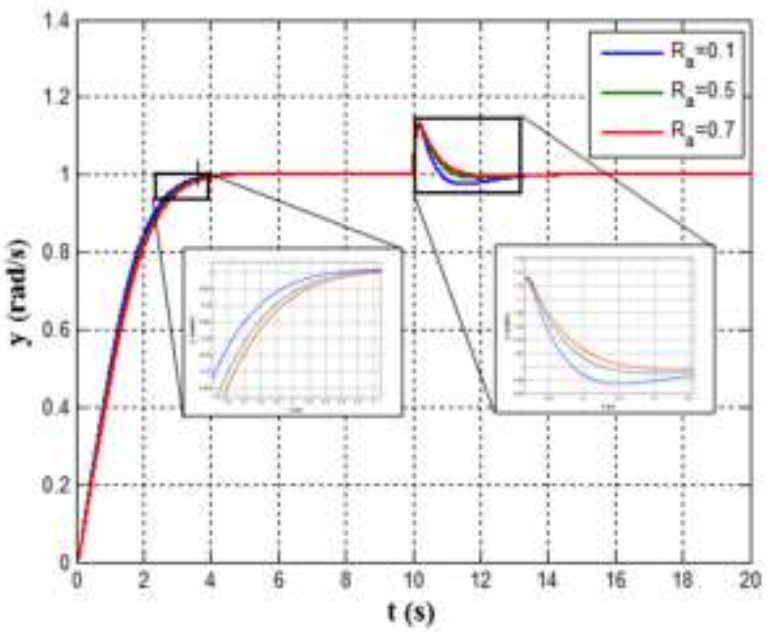

(a)

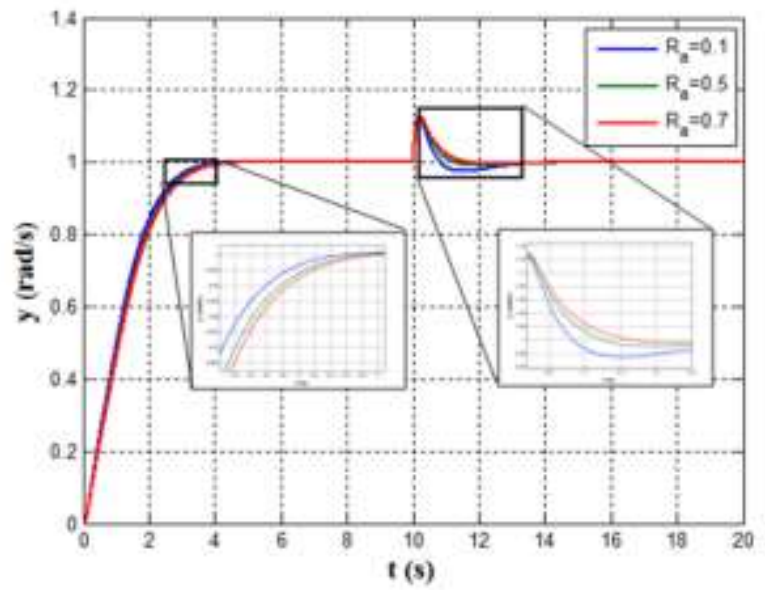

(b)

Fig. 13. The plant output $y$ in presence of uncertainty in the parameter $\mathrm{Ra}(\Omega)$, (a) for LESO (b) for SMESO

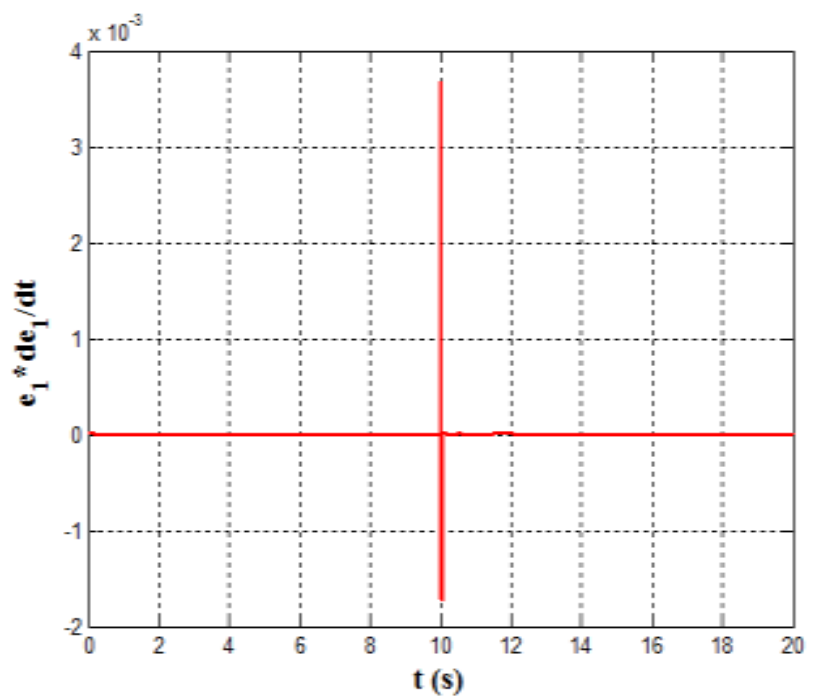

(a) 


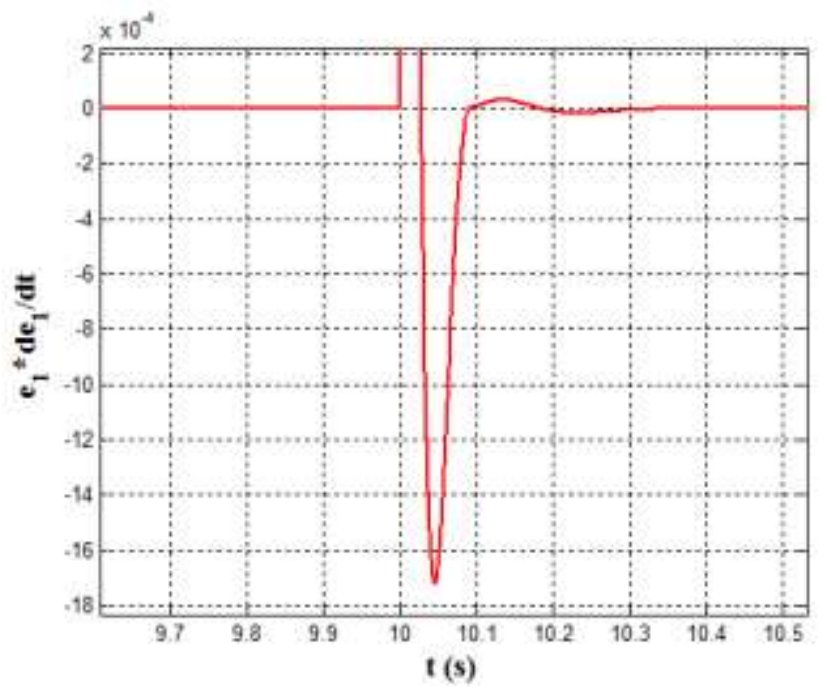

(b)

Fig. 14. The asymtoic stability characteristic of the prposed SMESO. for the prposed SMESO, (a) Plot of $e_{1} \dot{e}_{1}$ against time $\quad$ (b) close-up for $e_{1} \dot{e}_{1}$ around around the time of disturbance trigger $\mathrm{t}=10 \mathrm{sec}$

\section{CONCLUSIONS}

Through this work, we designed an active disturbance rejection control based on the sliding mode extended state observer (SMESO) for the PMDC motor. The basic idea of modified ADRC is to use the SMESO to guess, in real time, both the states of the system and the lumped disturbance (or extended state) which may arise from external disturbance, unknown system dynamics, and system parameters variations, and then cancelling all these uncertainties in the closed-loop feedback system. The SMESO is an extension of the LESO method, which as a state estimator; it performs better than the LESO observer in terms chattering reduction in the control signal. It has been proven that the estimation error is asymptotically convergent to zero under certain conditions in the nonlinear gain function. The estimation accuracy has been increased by adding the sliding term in the nonlinear extended state observer. It effectively rejects both matched uncertainties and exogenous disturbances without requiring any prior information about them and does not use an inverse model of the plant. Experimental results have shown that even the SMESO gives same performance in terms of timing and total disturbance rejection, the proposed method achieves an outstanding performance in terms of smoothness in the control signal which means less control energy is required to achieve the desired performance.

\section{ACKNOWLEDGEMENT}

The authors thank the electrical engineering department at the University of Baghdad for the direct support and encouragement.

\section{REFERENCES}

[1] Xie, L. L. , Guo, L.: 'How much uncertainty can be dealt with by feedback?', IEEE Trans. Autom. Control, Dec. 2000, 45, (12), pp. 22032217

[2] Gao, Z.: 'On the centrality of disturbance rejection in automatic control', ISA Trans., Jul. 2014., vol. 4, no. 53, pp. 850-857
[3] Li, S. H., Yang, J., Chen, W.H., et al.:'Disturbance Observer Based Control: Methods and Applications', Boca Raton, FL, USA: CRC Press, 2014.

[4] Chen, W., Yang, J., Guo, L., et al.: 'Disturbance-Observer-Based Control and Related Methods-An Overview', IEEE Transactions on Industrial Electronics, Feb. 2016, 63, (2).

[5] Khalil, H. K.,: 'High-gain observers in nonlinear feedback control'. New Directions in Nonlinear Observer Design, 1999,24,(4), pp. 249-268.

[6] Slotine, J. J. E. , Hednck, J. K., Misawa, E. A.: 'On sliding observers for nonlinear system', Journal of Dynamic Systems, Measurement, and Control, 1987, 109, pp. 245-252

[7] Radke, A., Gao, Z.: 'A survey of state and disturbance observers for practitioners'. American Control Conference, June 2006, pp. 5183 - 5188.

[8] Kalsi, K., Lian, J., Hui, S., et al.: 'Sliding-Mode Observers for Uncertain Systems'. American Control Conference, June 2009, pp. 10-12 .

[9] Wang, W., Gao, Z.: 'A comparison study of advanced state observer design techniques'. In Proceeding of the American Control Conference, Denver, Colorado, 2003, pp. 4754 - 4759.

[10] Huang, Y., Han, J.: 'Analysis and design for the second order nonlinear continuous extended states observer', Chinese Science Bulletin, 2000, 45, (21), pp. 1938-1944.

[11] Han, J.: 'From PID to active disturbance rejection control', IEEE Transactions on Industrial Electronics, 2009, 56, (3), pp. 900-906.

[12] Gao Z. : 'Scaling and Bandwidth Parametrization Based Controller tuning', IEEE, Proceedings of the ACC, Jun. 2003, 6, pp. 4989-4996.

[13] Xia, Y., Zhu, Z., Fu, M.: 'Back-stepping sliding mode control for missile systems based on an extended state observer', IET Control Theory and Applications, 2011, 5, (1), pp. 93-102

[14] Li, X., Li, S.: 'Extended state observer based adaptive control scheme for PMSM system'. Proceedings of the 33rd IEEE Chinese Control Conference, 2014.

[15] Guo, Z., Zhao, Z.L.: 'On convergence of non-linear extended state observer for multi-input-multi-output systems with uncertainty', IET Control Theory \& Applications, 2012, 6, (15), pp. 2375-2386.

[16] Han, J.: 'A class of extended state observers for uncertain systems', Control and Decision, 1995,10, (1), pp. 85-88.

[17] Hou, Y., Gao, Z., Jiang, F., et al.: 'Active disturbance rejection control for web tension regulation'. Proceedings of the 40th IEEE Conference on Decision and Control, Orlando, Florida USA, December 2001, pp. 49744979.

[18] Gao, Z. , Hu, S., Jiang., F.: 'A novel motion control design approach based on active disturbance rejection'. Proceedings of the 40th IEEE Conference on Decision and Control, Orlando, Florida USA, December 2001, pp. 4877-4882.

[19] Xia, Y., Shi, P. , Liu, G.P. , et al.: 'Active disturbance rejection control for uncertain multivariable systems with time-delay', IET Control Theory Appl., 1,(1), January 2007.

[20] Veluvolu, K.C., Soh, Y.C., Cao, W.: 'Robust observer with sliding mode estimation for nonlinear systems', IET Control Theory Appl., 2007, 1, (5), pp. 1533-1540.

[21] Xia, Y., Fu, M., Shi, P., et al.: 'Robust sliding mode control for uncertain discrete-time systems with time delay', IET Control Theory Appl., 2010, 4, (4), pp. 613-624.

[22] Yang, J., Chen, W.H., Li, S.: 'Non-linear disturbance observer-based robust control for systems with mismatched disturbances/uncertainties', IET Control Theory Appl., 2011, Vol. 5, Iss. 18, pp. 2053-2062.

[23] Dang, T. V. , Wang, W.J., Luoh, L., et al.: 'Adaptive observer design for the uncertain Takagi-Sugeno fuzzy system with output disturbance', IET Control Theory Appl., 2012, 6, (10), pp. 1351-1366.

[24] Wu, Y., Zheng, Q. : 'ADRC or adaptive controller - A simulation study on artificial blood pump,' Computers in Biology and Medicine, 2015, Vol. 66, pp. $135-143$.

[25] Zhang, C., Chen Y.: 'Tracking Control of Ball Screw Drives Using ADRC and Equivalent-Error-Model-Based Feedforward Control,' IEEE Transactions on Industrial Electronics, 2016, Vol. 63, Iss. 12.

[26] Rahman, M. M., Chowdhury, A. H.: 'Comparative study of ADRC and PID based Load Frequency Control', International Conference 
on Electrical Engineering and Information Communication Technology (ICEEICT), 2015.

[27] Shi. M., Liu, X., Shi, Y.: 'Research n Enhanced ADRC algorithm for hydraulic active suspension,' International Conference on Transportation, Mechanical, and Electrical Engineering (TMEE), 2011.

[28] Ahmed, A., Ullah, H. A., Haider I., et al.: 'Analysis of Middleware and ADRC based Techniques for Networked Control,' 16th International Conference on Sciences and Techniques of Automatic control \& computer engineering, At Tunisia, Vol. 16, 2015.
[29] Chenlu, W., Zengqiang, C., Qinglin, S., et al.: ' Design of PID and ADRC based quadrotor helicopter control system,' Control and Decision Conference (CCDC), 2016.

[30] Han. J.: 'From PID to Active Disturbance Rejection Control', IEEE Transactions on Industrial Electronics, March 2009, 56, (3).

[31] Mahfouz, A., Aly, A. , Salem, F. : 'Mechatronics Design of a Mobile Robot System', I.J. Intelligent Systems and Applications, 2013, 03,pp. 23-36. 